\title{
Are 'STEM from Mars and SSH from Venus'?: Challenging disciplinary stereotypes of research's social value
}

\author{
Julia Olmos-Peñuela ${ }^{1, *}$, Paul Benneworth ${ }^{2}$ and Elena Castro-Martínez ${ }^{1}$ \\ ${ }^{I}$ INGENIO (CSIC-UPV), Universitat Politècnica de València, Camino de Vera s/n, 46022 \\ Valencia, Spain. \\ ${ }^{2}$ Center for Higher Education Policy Studies, University of Twente, Enschede, The Netherlands. \\ *Corresponding author. Email: juolpe@ingenio.upv.es.
}

\begin{abstract}
There is a reasonably settled consensus within the innovation community that science, technology, engineering and mathematics (STEM) research is more 'useful' to societies than other types of research, notably social sciences and humanities (SSH) research. Our paper questions this assumption, and seeks to empirically test whether STEM researchers' practices make their research more useful than that of SSH researchers. A critical reading of the discussion around SSH research supports developing a taxonomy of differences. This is tested using a database of 1,583 researchers from the Spanish Council for Scientific Research. Results do not support the view that SSH research is less useful than STEM research, even if differences are found in the nature of both transfer practices and their research users. The assumption that STEM research is more useful than SSH research needs revision if research policy is to properly focus on research which is useful for society.
\end{abstract}

Keywords: research policy; user engagement; knowledge transfer; research utilisation; social sciences and humanities.

\section{Introduction}

Is science, technology, engineering and mathematics (STEM) research more useful to society than other types of research, notably social sciences and humanities (SSH) research? A recent provocation in Nature suggested that social science researchers were primarily concerned with disciplinary disagreements rather than contributing to solving contemporary societal problems (van Langenhove 2012). Research policy discourse certainly seems to assume that is true (Nightingale and Scott 2007). Indeed, in observing the policy discussion, one has the sense that there is almost a belief that STEM research is made from some kind of superior stuff, that STEM research is from the hard useful Mars whilst SSH research is a soft Venusian luxury (cf. Gray 1992). In this paper we explore the extent to which this assumption is valid. And, regardless of which side of the debate one finds oneself on, we believe that this policy assumption needs to be tested empirically.

We begin by contending that debate has been too constrained by indicators. Problems in finding suitable indicators have been used to infer that this means that $\mathrm{SSH}$ research has no impact. However, inspired by other research (Bate 2011; Hughes et al. 2011) we note the well-documented existence of engagement practices by SSH researchers, which imply relationships with 'users', and 'users' imply utility. We therefore see a potential contradiction here, as if SSH research were less useful than STEM research, then one would expect that there would be material differences in researchers' practices in ways that made that research less useful.

Our paper starts from the widely noted position that good indicators for measuring the impact of arts and humanities research are missing (Adviesraad voor 
Wetenschaps 2007; British Academy 2008; Crossick 2009; Algra et al. 2011; Bate 2011) and that oversimplistic indicators for SSH might cause important damage in these areas (Donovan 2005; British Academy 2008). This is not to say that indicators do not exist, but that they do not fulfil the definition used by van Vught and Westerheijden (2010) which allows for transparency and comparability between disciplines. This is where we see the problem in the debate - a failure to find appropriate 'transparent' impact indicators has become an assumption that $\mathrm{SSH}$ research does not have an impact, and is not socially useful or relevant (Hessels et al. 2009).

As a result, governments focusing on research that can drive economic growth (Kaiser and Prange-Gstöhl 2010; Directorate General Research 2011) are regarding SSH research as not worthy of investment. As argued more generally by O'Neill (2011: v):

... some held that in straitened times all public funding should go to research in science, technology, engineering and medicine.

When combined with van Langenhove's argument that social science research makes no useful contribution, this adds up to a powerful prescription to slash funding to the social sciences. But if it were based on a fallacy, then this policy would be wrong-headed, and therefore we argue that good science policy-making demands addressing the question of whether or not SSH research is less useful than STEM research.

We argue that this is not an issue which can be determined a priori. In this paper, we develop a set of empirical criteria which allow us to determine whether SSH research is less societally useful than STEM research. We then test this criteria set on a single empirical case, the Spanish Council for Scientific Research (CSIC). Our argument is that if the policy assumption holds, that STEM research is more useful than SSH research, then that will be visible in the comparative user engagement practices of STEM and SSH researchers. We argue that a 'user engagement practice' necessarily implies the existence of relationships with users, and the existence of 'users' implies that the research is useful to someone, itself a precondition for wider societal value. Thus, our framework offers a set of criteria that allow it to be empirically established whether SSH research is less useful or differently useful. In turn, this allows a contribution to be made to the urgent policy debate of whether the SSH are a priori less useful and therefore less worthy of funding, than STEM.

The structure of this paper is as follows. In Section 2 we classify disciplinary differences, distinguishing those that affect the social utility of their research from those that do not. In Section 3 we identify some stylised facts regarding SSH research differences which might account forfrom the theory - why this systematic disadvantage and bias afflicts the SSH. We then formulate hypotheses which are suitable for experimental testing. In Section 4 we present an overview of the data and methodology for this study and set out the variables used to test the hypotheses and their descriptive statistics. On the basis of the results about differences presented in Section 5, we then discuss them and offer some implications and policy recommendations in Section 6.

\section{SSH context in the science system}

Our starting point is that there is a policy problematic in assuming that the SSH lack of economic impacts means that they are less socially useful. Policy-makers seek macro-scale benefits, and economic outputs give them a way to claim these benefits. Policy-makers have internalised this message and sought to increase and concentrate funding on areas that bring the greatest, narrowly economic returns (Kaiser and Prange-Gstöhl 2010; Leisyte and Horta 2011). But this mistakenly suggests that the total societal returns to public investments in research are higher for STEM subjects. Spin-offs and patent licencing income have never been more than suggestive of a much wider and only partly economically calculable set of social benefits, that research brings (Pavitt 1991; Nightingale and Scott 2007). We therefore ask, taking a much wider reading of utility:

Is social sciences and humanities research different to science, technology, engineering and mathematics research in ways that make it systematically less useful to society?

There is extensive research suggesting that the SSH have real and broad impacts: for brevity's sake, we restrict our discussion to Spanish and British examples. In Spain, the SIAMPI project identified extensive impacts where clear public benefits were created, including in the cultural and heritage fields, neatly illustrated through examples from road and public safety. Public prosecutors worked with philosophy researchers at CSIC to provide deep understandings of the roots of driver behaviour in designing their strategies for dealing with traffic offenders. Work between police forensics research laboratories and a linguistic research group at CSIC contributed to increasing arrest and prosecution rates (Molas-Gallart et al. 2010). However, a SIAMPI report noted that whilst the preservation of the cultural heritage is a valuable impact, assessments considering its economic value depend on the extent to which popular demand for these cultural goods can be considered to be a crucial element in the impact assessment (Molas-Gallart et al. 2010).

In the UK context, there is a wealth of evidence that humanities research produces societally useful outputs (Hughes et al. 2011). Bate (2010) assembled 22 case studies of how particular research projects led to public outputs. In many cases the authors could enumerate these benefits: a vivid example was a piece of film 
research that led to a three-hour TV series watched by over a million viewers (Toulmin 2011). More generally, the UK's (statutory) Higher Education Business and Community Interaction Survey collects a suite of engagement activities counting attendances at lectures, exhibitions and museums run by universities.

SSH clearly produces benefits in terms of things that users value, although not always in ways that permit a simple traceability of macro-economic impacts. How can we interpret the fact that, although SSH research creates social impacts, an eminent public scientist such as van Langenhove (2012) can criticise their generic lack of utility? We ascribe this to a notion of difference, that STEM research is somehow different from SSH research. We therefore see that the problematic in the public policy debate can be stylised as a disagreement about the nature of this difference, corresponding to two positions:

- STEM research produces different kinds of outputs to SSH research (more easily traceable to macroeconomic impacts (Nightingale and Scott 2007; Hessels et al. 2009)).

- STEM research produces more useful outputs to SSH research (more people find their outputs more useful (van Langehoven 2012)).

We argue that the current policy debate has, for reasons of indicators, disregarded this issue of $\mathrm{SSH}$ research being differently useful to STEM research. We argue that these two positions can be regarded as two contradictory hypotheses which are empirically resolvable. And this is the issue that we test in this paper, whether SSH research is less useful than STEM research, or differently useful. To operationalise this idea of usefulness beyond narrow economic or monetary terms (which however imperfect and restricted, at least give a comparable measure of economic use), we are drawn into wider debates about the social value of research.

There are no good frameworks for comparing how publics value intangible benefits in non-economic ways, and therefore we restrict ourselves to only seeking to take a first step. We use researcher practices engaging with 'users' as a proxy for usefulness. If STEM research was really more useful to society than SSH research, then we would expect to find that STEM researchers' practices were more oriented towards users than those of SSH researchers. Hughes et al. (2011) suggest that this is not the case. We define 'users' as agents with whom researchers interact in the process of their knowledge flowing into society.

To sharpen that intuitive definition, in this paper we draw on Molas-Gallart and Tang (2011) and Spaapen and van Drooge (2011) for the idea of productive interactions as representations that research is useful to 'users': they define three types, namely personal contacts directly interacting with, audiences interacting with via artefacts, and customers engaged with through contracts with third parties. In this paper, for methodological reasons, we make a distinction between 'visible' users (i.e. direct contacts and contract partners) and 'invisible' audiences, based on the distinction of whether or not the researcher has a direct contact with the person receiving the knowledge.

\section{Differences in the research and transfer practices}

This then raises the issue of how practices would differ between STEM and SSH researchers? To do this, we explore the different types of 'claims' which various writers have made about differences between STEM and $\mathrm{SSH}$, and seek to draw them into a typology from which to derive hypotheses. These 'claims' are different types of entities: some are backed by more or less robust evidence, while some are policy narratives which have assumed the form of 'common sense'. Because we are dealing with claims made by actors in a policy discussion, we do not have a single model of how research produces impact. Rather, these relate to differences in practices that might reduce a SSH researcher's likelihood of doing research that at some point has some type of societal value.

In contrast to Olmos-Peñuela et al. (2012), and following our preceding argument, we classify these "claims for difference in practices' by making a simple distinction between whether they imply that STEM research is more useful, or simply differently useful:

- There are differences in practices which imply that STEM research is more useful than SSH research: differences in practices here support the hypothesis that STEM research is more useful than SSH research.

- There are differences in practices which imply that STEM research has a different way of making a societally beneficial contribution from $\mathrm{SSH}$ research: differences here support the hypothesis that STEM research is differently useful to $\mathrm{SSH}$ research.

We classify the eight claims about difference that are made into two groups: the first four suggesting that STEM research is more useful than SSH research, and the last four that STEM research is differently useful to SSH research. For each we give a brief explanation of the claim made, and derive a hypothesis in each case that SSH researcher practices is different to STEM researcher practices.

M1. SSH research is more oriented towards national/ regional audiences.

M2. SSH research tends to be less universal and to have smaller audiences.

M3. SSH research cannot give answers but only insights into problems.

M4. Lack of visibility of the contribution $\mathrm{SSH}$ research makes to social development. 
D1. SSH research does not need to try to be useful to be useful.

D2. SSH researchers collaborate less with business users who are a visible group.

D3. SSH researchers collaborate with government agencies rather than firms.

D4. SSH researchers collaborate with community users rather than firms.

\subsection{SSH tends to be more oriented to national/regional audiences}

In science policy contexts is assumed that the SSH are far more particular and specific than STEM, the latter producing universal laws and explanations. SSH and arts activities are especially important at closer geographical levels (British Academy 2004) and highly oriented towards regional or specific cultural communities. As noted by Edgar and Pattison (2006: 97-8):

The humanities still speak to specific communities, unlike the natural sciences that at least aspire to speak to a universal humanity... [humanities] still appear to speak in the voice of particular communities and about issues that concern particular communities.

SSH research is very often strongly context-oriented and not easily extrapolated to other regions or communities. A critical reading of Bate (2011) demonstrates a broad spectrum of research topics, each one confined to a very specific research and specific audience. Conversely, STEM knowledge can be used in generating knowledge that is:

... rooted in discovering increasingly and predictive universally applicable insights. (Bakhshi et al. 2008: 15)

According to this, we posit the following hypothesis:

H1: The rate of involvement with national users compared to international users is higher for $\mathrm{SSH}$ researchers than for STEM researchers.

\subsection{SSH tends to be less generalisable and to have smaller potential audiences}

The second claim made about SSH and arts research is that individual pieces of research are not easily scalable. Thus, a research project produces an exhibition that attracts a number of visitors, but the public life of that knowledge then ends (Bakhshi et al. 2008), in contrast to STEM research which endures. Here the claim is that SSH and arts research is intrinsically less useful because there are fewer potential users, meaning smaller impacts and users or audiences than for STEM research with its universalist possibilities (Bakhshi et al. 2008). Indeed, Hughes et al. (2011) find that UK arts and humanities researchers reported more often that their research was irrelevant for external organisations. Likewise, the SIAMPI project illustrates this characteristic through the example of the discovery, translation and publication of 16th century Spanish music and the limited audience interested in it (Molas-Gallart et al. 2010). Hence our second hypothesis is that SSH researchers feel that few non-academic entities are interested in their specific research, that is:

$\mathrm{H} 2$ : $\mathrm{SSH}$ researchers experience a lower demand for their research than is the case for STEM researchers.

\subsection{SSH research does not give concrete answers, rather it provides insights into problems}

One of the key problems is that different SSH disciplines purport to be able to talk authoritatively about the same subjects but different fields have quite different ways of looking at those subjects. The great example is economics, where one's theoretical perspective produces wildly differing interpretations of similar events: a very confusing message for policy-makers, and clearly contrasting with STEM research's clear laws and universals. Some subjects use hermeneutic, inductive approaches, as noted by Bakhshi et al. (2009: 110):

...the arts and humanities develop and re-evaluate earlier ideas and sources of evidence, viewing them from new perspectives and new contexts.

For the public, the STEM disciplines give hard answers to questions without this grey area for interpretation and are regarded as authorities in their fields. Conversely, SSH researchers become one voice amongst many in a crowded global marketplace of ideas, with their opinions being equal to those of think-tanks or lobbyists.

Therefore the claim is that SSH disciplines talk less authoritatively about the world, reducing the utility of their knowledge by being contingent and disputed rather than universal and established. Of course, it could also be claimed that the subject domain of the $\mathrm{SSH}$ is more complex and less knowable, and a diversity of approaches provides depth in understanding the issues and problems. But a set of claims that SSH is more akin to interpretations whilst STEM research is more authoritative is still circulating. We would expect SSH researchers to feel more threatened by having to test the validity of their research than would STEM researchers. Thus, we suggest the following hypothesis:

$\mathrm{H} 3$ : SSH researchers have less interest in checking the validity and applicability of their research than do STEM researchers.

\subsection{The lack of visibility of SSH's contribution to social development}

The last difference claim that implies that STEM research is more useful than SSH research is the lack of visibility of $\mathrm{SSH}$ research that leads to its under-utilisation. SSH 
disciplines are too often too far from their eventual users, which reduces the visibility of their research output. This claim is a version of the argument that SSH research is more theoretical and relates more exclusively to solving theoretical rather than practical problems. Based on the Frascati Manual classification of basic/applied research (OECD 2002), Gulbrandsen and Kyvik (2010) found that in Norwegian universities, compared to other fields, a larger proportion of humanities academics classified their activities as 'basic'.

An alternative categorisation is the Stokes quadrant model $(1997)^{1}$ that classifies research along two dimensions (theoretical excellence and practical relevance), that has been used in previous studies (Abreu et al. 2009; Hughes et al. 2011). Hughes et al. (2011) find that academics from the arts and humanities describe their research as basic, with a higher orientation to the pursuit of fundamental understanding (Bohr quadrant) compared to the rest of the areas. Then, we would expect to find STEM researchers located in the Edison or Pasteur quadrants, if they are more concerned with considerations of use and relevance whilst $\mathrm{SSH}$ researchers to be more oriented to basic and excellent research which corresponds to the Bohr quadrant. We therefore posit the following hypothesis:

H4: SSH researchers are more concerned with the pursuit of fundamental understanding whereas STEM researchers are more focused on considerations of use.

Of course, there is a counter-claim here, namely that the SSH do not readily fit into to a simple STEM-derived technology transfer or knowledge transfer model (Hartley and Cunningham 2001; Bakhshi et al. 2009; Jaaniste 2009). The dominant model focuses on narrow indicators, only counting formalised and transactional activities, that is to say contractual relationships between an academic unit and a non-academic agent in a way that creates a legal entity that can easily be countedsuch as a contract, patent license, non-disclosure agreement or co-operative heads of agreement. However, these institutionalised knowledge transfer activities (Geuna and Muscio 2009) only represent a fraction of the universities' full suite of interactions with, and impacts upon, society (D'Este and Patel 2007; Perkmann and Walsh 2007) and ignore more informal collaborations. Tacit knowledge plays a more prominent role in the SSH and arts than it does in STEM (Arts and Humanities Research Council 2009: 15) hence, the SSH are characterised by a lower level of codified research (Pilegaard et al. 2010) and a higher relevance of personal contacts between researchers and users (British Academy 2008). Indeed, the SSH is dominated by informal collaborations that do not leave an audit trail (Castro-Martínez et al. 2011). Conversely, STEM research gives tangible products or technologies that require formal protection of intellectual property rights. Indeed, a recent study conducted in the UK context (Abreu and Grinevich 2013) show lower levels of engagement of SSH researchers in formal commercial activities compared to other sciences and engineering disciplines. Therefore, in a context where science's contribution is measured through narrow transactional indicators (SSH is dominated by informal collaborations and STEM researchers are more likely to use formalised interactions), we propose the following hypothesis:

H5: SSH researchers use a lower proportion of formal pathways to interact with non-academic actors compared to STEM researchers.

\subsection{The usefulness of the SSH is delivered by their not trying to be useful}

One claim often made by advocates of the $\mathrm{SSH}$ is that unlike STEM disciplines, SSH claim to have a higher purpose beyond the direct and visible application to economic growth. They provide a lens enabling society to understand generic and fundamental questions about the past, the present and the future, and about the ethical and cultural values that shape society (Bigelow 1998, cited in Bullen et al. 2004; British Academy 2004). SSH researchers are:

... opinion-makers and are called upon everyday media as experts. (Stannage and Gare 2001: 111)

They address issues such the economic crisis, unemployment, immigration, and other social problems (Kyvik 1994; 2005). Conversely, STEM research is more weakly linked to current events or to understanding a contemporary social phenomenon: consider the recent discovery of the Higgs boson - the event was its discovery and all media engagement depended on when it was found. According to previous studies, SSH researchers would be more engaged in popularisation activities such as radio, TV, press and conference activities whereas STEM researchers would be more represented in institutional activities such as 'open door' events (Jensen and Croissant 2007: 4). Consequently we posit the following hypothesis:

H6: SSH researchers spend more time in popularisation activities than do STEM researchers.

\subsection{Business users are a more visible group than government or community}

Another claim that arises about differences between areas is related to the non-academic actors with whom researchers collaborate. STEM research tends to have a greater common form of engagement, via firms, whilst the contributions of the SSH are more diverse, coming through different types of contributions through the public and voluntary sectors as well as directly with publics through engagement. Our argument is that $\mathrm{SSH}$ 
research appears to be less useful because it has a less singular form of engagement (with diverse groups), whilst STEM subjects benefit from having collaboration activities with firms, which are a collective more amenable to aggregation by policy-makers. Hence, the following hypotheses are proposed:

H7a: SSH researchers collaborate less with firms than do STEM researchers.

H7b: SSH researchers use fewer pathways collaborating with firms than do STEM researchers.

\subsection{SSH research users tend to be government agencies}

A simple way of expressing this claim is the frequently evoked image of the humanities as an ivory tower, and the SSH as disconnected from society. There is no interaction between academics and non-academics in these disciplines, additionally, the SSH disciplines do not make a socio-economic contribution. However, that assumption, apparently deriving from technology transfer and knowledge transfer studies, primarily focused on universityindustry relationships rather than a wider set of users (Hughes et al. 2011). The range of potential users of academic research can be expanded to all science-society interactions including government agencies (see British Academy (2008) for further details on the contribution of the SSH to public policy). Indeed, in the Australian context government department and agencies are the most frequently cited clients of the $\mathrm{SSH}$ and arts (Gascoigne and Metcalfe 2005), and in the British context, arts and humanities are more involved with the public sector $(38 \%)$ than with the private sector $(30 \%)$ (Hughes et al. 2011). From this literature, we posit the following hypotheses:

H8a: The frequency of collaborations with government agencies compared to firms is higher for $\mathrm{SSH}$ researchers than for STEM researchers.

H8b: SSH researchers use more pathways collaborating with government agencies than do STEM researchers.

\subsection{SSH research users tend to be community users}

As indicated in Section 3.7, we find a very diverse 'set' of users of SSH research if we consider science-society interactions rather than science-industry interactions. By expanding this approach, we identify a variety of users varying in terms of their economic power, their ability to engage academics, and their motivation to work with them. Other than the public sector (see Section 3.7), the SSH are closely linked to community users such as nonprofit organisations, as shown in the Spanish context (Castro-Martínez et al. 2011). Moreover, in the British context, arts and humanities academics are highly engaged with the charitable sector (46\%) (Hughes et al. 2011). Based on previous studies, we suggest the following hypotheses:

H9a: The frequency of collaborations with non-profit organisations compared to firms is higher for $\mathrm{SSH}$ researchers than for STEM researchers.

H9b: SSH researchers use more pathways collaborating with non-profit organisations than STEM researchers.

Our argument is that these claims are clearly overlapping and provide a means to identify whether SSH researchers' practices do differ from that of STEM researchers and in which areas. Thus, although some of the hypotheses might seem obvious, what is important is the composition of the ways in which differences in practices in aggregate vary between the two groups. A full summary of these nine hypotheses is presented in the Appendix (Table A1). The hypotheses were tested using a database of researchers working at the CSIC. In order to better frame the testing process, we now provide an explanation of the construction of the variables and the dataset.

\section{Data and methodology}

\subsection{Population and data collection}

The empirical study focused on the CSIC, the largest public research organisation in Spain and the third largest in Europe. CSIC emerged in 1939 after the civil war, and was built on the remnants of the research centres of the dissolved Junta de Ampliación de estudios (created in 1907). The mission of the CSIC is to develop and promote research through its institutes in the interest of scientific and technological progress. In 2011, CSIC had 126 research institutes distributed throughout Spain and had 14,050 employees distributed as civil servants (41.9\%), contract workers $(50.3 \%)$ and research fellows $(7.8 \%)$. The CSIC is distributed across eight main areas of knowledge. ${ }^{2}$ In economic terms, its resources in 2011 came from direct transfers from the government budget $(60 \%)$ and external resources $(40 \%)$ coming from regional, national, and international competitive $\mathrm{R} \& \mathrm{D}$ programmes and contracts with companies and organisations (CSIC 2012). Compared to Spanish universities, the CSIC performed better in terms of contracts with public and private entities, in the number of patents registered and internationalised, and in technology licencing. Furthermore, CSIC generates $20 \%$ of the Spanish scientific output from $6 \%$ of the total number of staff engaged in funded R\&D in Spain.

We use a recent database assembled by two institutes ${ }^{3}$ from the CSIC in the framework of the IMPACTO project, commissioned by the CSIC. The project aims to empirically determine the nature and characteristics of CSIC researchers' relationships with firms, government agencies and other social agents as well as the factors affecting them. We consider that this database is suitable to 
use for an exploratory analysis to test differences between SSH and STEM researchers since it directly tackles the aspects addressed through our hypotheses and since data allows comparison by area of knowledge. More specifically, the database contains the answers from scientific researchers (civil servants ${ }^{4}$ or researchers contracted through JAE-Doc, Juan de la Cierva, Ramón y Cajal or similar post-doctoral programmes) with a doctoral degree and the right to act as principal researchers and enter into contracts with other entities. On 30 November 2010 the CSIC Human Resources Department identified a total of 4,240 researchers who met these requirements.

A questionnaire was developed from a literature review on the effects of public research, built on conceptual foundations analysing the role of public research in business $\mathrm{R} \& \mathrm{D}$ and innovation processes, with a special emphasis on those studies that reflect different transfer mechanisms and their impacts (Bonaccorsi and Piccaluga 1994; Cohen et al. 2002; Schartinger et al. 2002; Azagra-Caro 2007; D'Este and Patel 2007). Following the theoretical and empirical review, five main conceptual dimensions were identified and included in the questionnaire: researchers' profile and their research activities; researchers' relationships with non-academic agents; barriers to establishing relationships; engagement in dissemination activities; and results of the researchers' relationships with their socioeconomic environment (see the Appendix (Table A2) for further details on the structure of the questionnaire).

Two contextual conditions would suggest the questionnaire was well understood by its respondents. First, the questionnaire is addressed to the academic community, who share the same language to address topics related to research and collaborative practices. Second, the implementation of the CSIC Institutional Action Plan (2006-9) had sensitised the researchers to the questionnaire's concepts and terminology. We also conducted a pre-test of the questionnaire on 45 CSIC researchers of the different scientific areas of knowledge in which the CSIC is structured, to ensure that all the questions were well understood by respondents. Researchers completed the test questionnaire and then participated in a telephone interview in which they provided their opinion about the questionnaire.

Societal usefulness is a relevant topic in the policy agenda of the CSIC and the implementation of instruments to measure engagement may mean that CSIC researchers tend to report an overly positive attitude towards this agenda in their responses to the questionnaire. However, we are confident that this has not been the case for the following reasons. First, the historic mission of the CSIC of conducting useful research and contributing to the societal development is not new; therefore, researchers have always had these values embedded in their practices to some extent. Second, the autonomy of individual researchers, based on both their tenured positions and their independent access to national and international competitive research funding, may also reduce their sense of obligation to provide an answer compatible with current research governance regarding the usefulness agenda. Finally, the 16 pilot interviews conducted at the beginning of the project reflected the fact that the researchers were adopting a critical position on the discourse of usefulness and engagement, which is likely to have reduced any unduly positive bias in the answers reported.

Data collection took place in the period 7 April 2011 to 24 May 2011 through the population emails provided by the CSIC Human Resources Department. The strategy used for data collection was multi-method. It combining online questionnaires with telephone follow-up to ensure that the final sample was proportionally distributed by areas of knowledge and professional categories. Given the relevance of multiple contacts with the respondents to maximise responses to email surveys (Dillman 2007), an invitation email was sent from the presidency of CISC to all the population, followed by the online questionnaire, two reminder emails to the population who did not respond and a final follow-up by telephone. The final response rate was $37 \%$, corresponding to a sample covering 1,583 researchers. The population and sample distribution by area of knowledge is reported in Table 1 . Chi square tests confirm that there are no statistical differences between the population and sample distribution by scientific area of knowledge (nor within the SSH fields), except for agricultural science which is slightly overrepresented in the sample.

Of course, using this database imposes some limitations on the validity of our findings, and for the sake of completeness we explicate these shortcomings. First, the database only includes CSIC researchers, university researchers were not included. But focusing on CSIC allows us to obtain a homogenous population, subject to the same contextual conditions, which is preferable for exploring the validity of our hypotheses. Secondly, all scientific fields are not equally represented in CSIC: but this is a common feature in academic organisations in which some areas of knowledge have a stronger presence than others. In this sense, the sample obtained is a version of reality as its composition reflects CSIC's structure by scientific areas of knowledge. Thirdly, we are using an existing database in which the questions predated our paper. This limitation is partly (and we believe sufficiently) mitigated by the adequacy of the questionnaire from which the database is constructed. It is exclusively restricted to two types of users, partners and customers (i.e. direct interactions) rather than audiences engaged with at a distance (Spaapen and van Drooge 2011). Nevertheless, the questionnaire covers researchers' practices and collaborations with non-academic agents, which are the aspects addressed in all the hypotheses proposed. Moreover, all scientific fields are covered in the database, which allow us to make comparisons between STEM and SSH researchers. On balance, we consider that 
Table 1. Population and sample distribution by area of knowledge

\begin{tabular}{|c|c|c|c|c|c|}
\hline & $\begin{array}{l}\text { Population } \\
\text { (N) }\end{array}$ & $\begin{array}{l}\text { Population } \\
(\%)\end{array}$ & $\begin{array}{l}\text { Sample } \\
\text { (N) }\end{array}$ & $\begin{array}{l}\text { Sample } \\
(\%)\end{array}$ & $\begin{array}{l}\% \text { differences } \\
\chi^{2} \text { test }(*)\end{array}$ \\
\hline STEM & 3,838 & $90.5 \%$ & 1,466 & $92.6 \%$ & $2.1 \%$ \\
\hline Biology and biomedicine & 771 & $18.2 \%$ & 244 & $15.4 \%$ & $-2.8 \%$ \\
\hline Food science and technology & 285 & $6.7 \%$ & 128 & $8.1 \%$ & $1.4 \%$ \\
\hline Materials science and technology & 562 & $13.3 \%$ & 201 & $12.7 \%$ & $-0.6 \%$ \\
\hline Physical science and technology & 569 & $13.4 \%$ & 204 & $12.9 \%$ & $-0.5 \%$ \\
\hline Chemical science and technology & 480 & $11.3 \%$ & 209 & $13.2 \%$ & $1.9 \%$ \\
\hline Agricultural sciences & 412 & $9.7 \%$ & 203 & $12.8 \%$ & $3.1 \% *$ \\
\hline Natural resources & 759 & $17.9 \%$ & 277 & $17.5 \%$ & $-0.4 \%$ \\
\hline SSH & 402 & $9.5 \%$ & 117 & $7.4 \%$ & $-2.1 \%$ \\
\hline Social sciences & 127 & $3.0 \%$ & 40 & $2.5 \%$ & $-0.5 \%$ \\
\hline Humanities & 275 & $6.5 \%$ & 77 & $4.9 \%$ & $-1.6 \%$ \\
\hline Total & 4,240 & & 1,583 & & \\
\hline
\end{tabular}

$\chi^{2}$ test has been used to assess whether there are differences between population and sample distribution for each area of knowledge

$*$ indicates statistical differences at $5 \%$. Agricultural sciences are statistically overrepresented in sample

despite these limitations, it is still reasonable to propose using the CSIC database as the foundation for our exploratory analysis. We now present the variables used in the questionnaire to test the hypotheses proposed.

\subsection{Variables and test considerations}

We used a number of variables constructed from the CSIC questionnaire to test the proposed hypotheses. In constructing each variable we have taken the nine hypotheses, and sought to identify a question from the questionnaire which allows us to see practices relevant to that hypothesis. We argue that each variable represents one practice within the set of all practices that might correspond to each hypothesis, but that it is not necessarily the best variable. We justify this on the grounds of this being a piece of exploratory research seeking to understand whether differences in practice do exist, and if so, then what their apparent ramifications are. We would not advocate using these variables as a complete measure of user engagement practices, and we would not, at this stage, recommend adopting them more widely as 'indicators' for social value. Detailed definitions of the variables are given in Table 2 .

All the variables used to test the hypotheses are ordinal or continuous variables except for the variable referred to the Stokes quadrant. Therefore, for ordinal and continuous variables (distributions not matching with a normal distribution) we use the Mann Whitney test (U) to statistically assess whether there are differences in the sampling distribution of the different variables for SSH and STEM areas. For the categorical variable [Stokes quadrant] we use the independency Chi square test $\left(\chi^{2}\right)$ to assess whether there are similarities between SSH and STEM researchers in their distribution between the four categories proposed by Stokes (1997): Linnaeus (Alrøe and Kristensen 2002), Edison, Bohr and Pasteur.

\section{Empirical results}

\subsection{Descriptive statistics}

The descriptive statistics of the variables used in this study corresponding to all areas are reported in Table 3. The weight of SSH researchers in the whole sample is $7.4 \%$. More than half of the researchers were reported to be in the Bohr quadrant (research highly inspired by fundamental understanding and lowly by consideration of use), followed by the Pasteur quadrant with $22.2 \%$ and Edison quadrant with $9.7 \%$. The average percentage of time spent by researchers on popularisation activities is $4.04 \%$.

More than $80 \%$ of the respondents declare that checking the validity or practical application of the research developed is an important or very important motivation to establish relationships with other entities. Likewise, more than half of the researchers report as quite or a lot as the extent to which the lack of interest shown in their research by others is an obstacle to establishing relationships with them.

In their relationships with non-academic entities, $43 \%$ of the pathways of collaboration used by researchers are formal. The average ratio of research collaborations with national entities, in comparison with international entities is $72 \%$. Slightly less than one-quarter of the respondents had not collaborated with firms over the last three years whereas almost $15 \%$ had done so seven times or more. Indeed, the most frequent case is to collaborate with firms one to three times in the considered period. Moreover, on average, the respondents score 2.60 of a possible maximum of 14 on the variety index for collaborative activities with firms.

Related to the rate of collaborations with agents other than firms, we find on average that the ratio of researchers' collaborations with government agencies and 
Table 2. Definitions of variables

Variables

Continuous variables

National orientation
The number of different types of national entities divided by the number of different types of international entities with whom the researcher has collaborated over the last 3 years. This variable is constructed following a three-step procedure. First, we codified in binary variables 5 assertions regarding the researcher's collaborations with different national entities and international entities. Therefore, we coded each variable ' 1 ' if the researcher indicated that he had collaborated with at least one of the following entities: firms located in Spain; government agencies; non-profit organisation; firms located outside of Spain; and international organisation, over the last 3 years; and ' 0 ' otherwise. Secondly, three of these binary variables are used to construct a three-item variety index ranging between 0 and 3 (national entities) regarding whether or not a researcher has collaborated over the last 3 years with the following national entities: 1) firms located in Spain; 2) government organisation; 3) non-profit organisation. The two remaining entities named firms located outside of Spain and international organisation are used to construct a two-item variety index ranging between 0 and 2 (international entities) regarding whether or not a researcher has collaborated over the last 3 years with these two international entities. Thirdly, the variable [National orientation] is then constructed as a percentage by using the following formula:

$[$ National orientation $]=($ national entities $) /($ international entities $) \times 100$

Formality

The percentage of the formal pathways used by a researcher to collaborate with nonacademics related to the total pathways used over the last three years. This variable is constructed following a three-step procedure. First, we codified in binary variables, 14 assertions regarding the researcher's collaborations activities with different entities. Therefore, we coded each variable ' 1 ' if the researcher indicated that he had collaborated with at least one of the following entities: firms, government agencies, international organisations or non-profit organisations, over the last 3 years; and ' 0 ' otherwise. Secondly, 8 of these binary variables are used to construct an eight-item variety index ranging between 0 and 8 (formal pathways) regarding whether or not a researcher has developed the following collaborative activities with firms, government agencies, international organisations or non-profit organisations over the last 3 years:

- Contract research (original research project totally sponsored by the contracting entity)

- Collaborative research funded by a Spanish public program

- Collaborative research funded by international programs (Framework Programme or similar)

- Courses and specialised training activities taught by the CSIC

- Use of CSIC infrastructures or equipment by this entity

- License of patents (or other types of intellectual property protection)

- Creation of a new firm in partnership

- Participation in the creation of a new centre or joint unit of R\&D

The six remaining binary variables are used to construct a six-item variety index ranging between 0 and 6 (informal pathways) regarding whether or not a researcher has developed the following collaborative activities with firms, government agencies, international organisations or non-profit organisations over the last 3 years:

- Occasional contacts or consultations (not formalised through a contract or an agreement)

- Technical services, technical reports or technological support

- Temporary stay of a person of your team outside the academy

- Training of postgraduates outside the academy (including PhD thesis)

- Consultancy through committees and expert meetings

- Participation in diffusion activities in professional environment (congress or professional conferences, trade fairs)

Thirdly, the variable [Formality] is then constructed as a percentage by using the following formula:

$$
[\text { Formality }]=(\text { formal pathways }) /(\text { formal pathways }+ \text { informal pathways }) \times 100
$$

Ratio 
Table 2. Continued

Variables Measure Method (range)

Popularisation

Government agencies

NPO

Diversity of pathways of interactions with:

a) Firms;

b) Government agencies;

c) NPO

Categorical variables User demand

Check validity

Stokes quadrant

Firms

Area
- Measured as the percentage of time spent by the researcher on popularisation activities (e.g. publications of articles in newspapers or in textbooks, participation in radio or TV programmes, in 'science weeks' etc.)

- Measured as the frequency of collaborations with government agencies divided by the frequency of collaborations with firms located in Spain over the last 3 years. The frequency of these collaborations are both measured using a 4-point Likert scale ranging from ' 1 ' = Zero times to ' 4 ' = Seven or more times

- Measured as the frequency of collaborations with non-profit organisations divided by the frequency of collaborations with firms located in Spain over the last 3 years. The frequency of these collaborations are both measured using a 4-point Likert scale ranging from ' 1 ' = Zero times to '4' = Seven or more times

Measured using a 14-item variety index regarding whether or not the researcher has collaborate in different activities with: a) firms; b) government agencies; c) non-profit organisations; over the last 3 years. The activities included are the 14 items previously used in the definition of the variable [Formality]

- Measured using a 4-point Likert scale ranging from ' 1 ' $=$ Not at all to ' 4 ' $=$ A lot to indicate the answer of the researcher to the following question: 'To what extent the little interest of other entities about your research is an obstacle to establish relationships with other entities?'

- Measured using a 4-point Likert scale ranging from ' 1 ' = Not important to ' 4 ' = Very important to indicate the degree of importance for the researchers of the following assertion: 'the motivation to establish relationships with other entities is to check the validity or practical application of the research developed.'

- Categorical variable coded ' 1 ' if the researcher's research is classified in Linnaeus quadrant; '2' in Edison's quadrant; ' 3 ' in Bohr's quadrant and '4' in Pasteur's quadrant (see Appendix 2, Q.1)

The variable [Stokes quadrant] is operationalised by using two variables: 1). the extent to which scientific activity is inspired by making contributions to fundamental understanding; and 2). the extent to which researcher activity is inspired by considerations of use.

The construction of the categorical variable [Stokes quadrant] used in this paper is based on these two variables and was derived in a two-step process. First, we codified both variables ('fundamental understanding' and 'considerations of use') into ' 1 ' (high) if the researcher has answered 'a lot' and ' 0 ' (low) otherwise.

Second, the 4 configurations of scientific research orientation were characterized by combining the 2 variables in the following manner:

- Linnaeus quadrant: low fundamental understanding and low consideration of use

- Edison quadrant: low fundamental understanding and high consideration of use

- Bohr quadrant: high fundamental understanding and low consideration of use

- Pasteur quadrant: high fundamental understanding and high consideration of use

- Measured using a 4-point Likert scale ranging from ' 1 ' = Zero times to ' 4 ' = Seven or more times to indicate the frequency with which a researcher has collaborated with firms located in Spain over the last 3 years

Dichotomous variable:

- coded ' 1 ' if the researcher belongs to the SSH area and ' 0 ' if the researcher belongs to the STEM area. STEM area encompasses the following sub-areas: 1) biology and biomedicine; 2) food science and technology; 3) materials science and technology; 4) physical science and technology; 5) chemical science and technology; 6) agricultural sciences; 7) natural resources
Ratio

Ratio

Ratio

Sum $(0-14)$

Ordinal (scale ranges between 1 and 4)

Ordinal (scale ranges between 1 and 4)

Nominal

Ordinal (scale ranges between 1 and 4)

Binary 
Table 3. Descriptive statistics

\begin{tabular}{|c|c|c|c|}
\hline Continuous variables & Type of variables & Mean & Standard deviation \\
\hline - National orientation & Continuous: number & 72.11 & 21.918 \\
\hline - Formality & Continuous: number & 43.31 & 17.944 \\
\hline - Popularisation & Continuous: number & 4.04 & 6.635 \\
\hline - Government agencies & Continuous: number & 1.21 & 0.731 \\
\hline - NPO & Continuous: number & 0.86 & 0.533 \\
\hline - Firms_pathways & Index: 14 items & 2.60 & 2.519 \\
\hline - Government_pathways & Index: 14 items & 4.15 & 3.024 \\
\hline - NPO_pathways & Index: 14 items & 0.78 & 1.564 \\
\hline $\begin{array}{c}\text { Categorical variables } \\
\bullet \text { User demand }\end{array}$ & $\begin{array}{l}\text { - Not at all } \\
\text { - A little } \\
\text { - Quite } \\
\text { - A lot }\end{array}$ & $\begin{array}{l}\text { Distribution } \\
14.4 \% \\
31.3 \% \\
35.3 \% \\
19.0 \%\end{array}$ & $\begin{array}{l}\text { Median } \\
\text { Quite }\end{array}$ \\
\hline - Check validity & $\begin{array}{l}\text { - Not important } \\
\text { - Some important } \\
\text { - Important } \\
\text { - Very important }\end{array}$ & $\begin{array}{l}2.7 \% \\
15.7 \% \\
48.8 \% \\
32.8 \%\end{array}$ & Important \\
\hline - Stokes quadrant & $\begin{array}{l}\text { - Linnaeus } \\
\text { - Edison } \\
\text { - Bohr } \\
\text { - Pasteur }\end{array}$ & $\begin{array}{l}10.0 \% \\
9.7 \% \\
58.1 \% \\
22.2 \%\end{array}$ & \\
\hline - Firms & $\begin{array}{l}\text { - } 0 \text { times } \\
\text { - } 1-3 \text { times } \\
\text { - } 4-6 \text { times } \\
\text { - } 7 \text { or more times }\end{array}$ & $\begin{array}{l}23.8 \% \\
42.4 \% \\
18.9 \% \\
14.9 \%\end{array}$ & 1-3 times \\
\hline - Area & $\begin{array}{ll}\text { - } & S S H \\
\text { - } & S T E M\end{array}$ & $\begin{array}{l}7.4 \% \\
92.6 \%\end{array}$ & \\
\hline
\end{tabular}

These descriptive statistics are referred to the whole sample: SSH and STEM taken together

non-profit organisations (NPOs), in comparison with firms, is 1.18 and 0.84 , respectively. Focusing on the diversity of researchers' pathways of collaborations, results indicate that respondents score 4.15 and 0.78 of a possible maximum of 14 on the variety index of collaborative activities with government agencies and NPOs, respectively.

\subsection{Statistical tests}

To empirically test the hypotheses formulated, we apply the independence Chi square test $\left(\chi^{2}\right)$ to assess $\mathrm{H} 4$, that is, the independence or not between SSH researchers and STEM researchers in their position in the Stokes quadrant. The null hypothesis here is that there is independency between the two groups and is rejected if the p-value $<0.05$. A Mann-Whitney test (U) is applied for $\mathrm{H} 1-\mathrm{H} 3$ and $\mathrm{H} 5-\mathrm{H} 9$ to establish whether there are statistically significant differences between SSH and STEM researchers. It should be noted that for these hypotheses the null hypothesis is that there are no differences between SSH and STEM research and is rejected if the p-value $<0.05$. Results are presented in Table 4 .
5.2.1 Are STEM disciplines more useful than SSH disciplines? The first set of hypotheses tested is related to whether STEM research is more useful than SSH research. For the variable [National orientation] there is evidence that there are differences in favour of the national orientation of SSH research. We reject the null hypothesis (H1) about the regional or national orientation of SSH as the $\mathrm{p}$-value is 0.00 . This is the only piece of evidence that suggests that SSH research might be less useful than STEM research, by being primarily oriented to national users rather than international users. For the remaining three utility indicators, there is no evidence to reject the hypotheses that SSH and STEM researchers' practices are similar.

For the variable [User demand] measuring researchers' perception of the interest of users in their research, we cannot reject the null hypothesis (H2) as the $\mathrm{p}$-value is 0.35 . The literature predicted that $\mathrm{SSH}$ researchers would feel less interest or demand from users for their research than STEM researchers (Hughes et al. 2011). Nevertheless, this is not supported by our evidence and we have to move towards rejecting this hypothesis. 


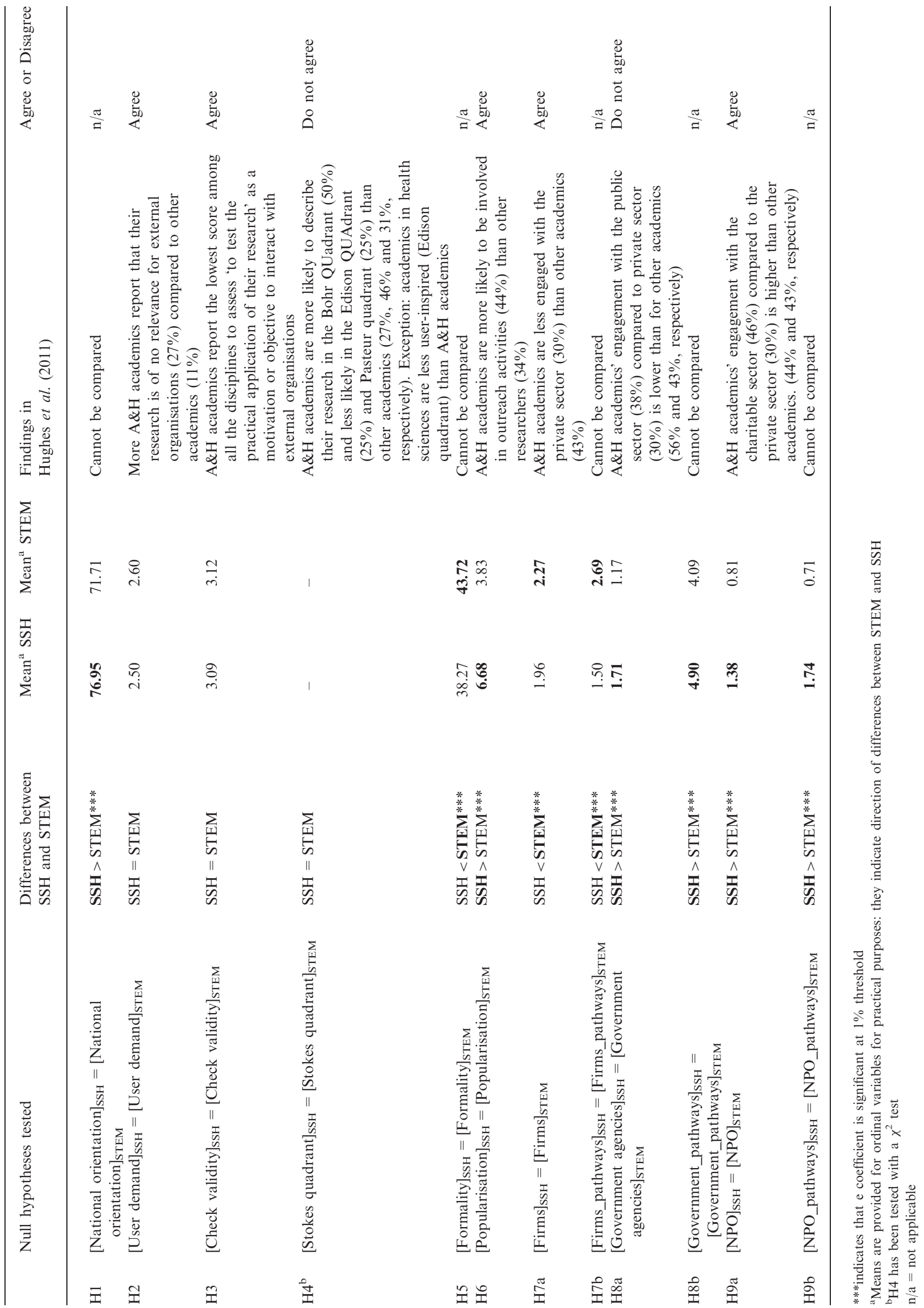


For hypothesis H3 [Check validity] we cannot reject the null hypothesis as we obtain a p-value of 0.57. From our review, our starting hypothesis was that SSH researchers would be less interested in validating their research with users than would STEM researchers. As SSH researchers conduct research regarded as less authoritative, we expected that they would be less interested than STEM researchers in checking the applicability of their research. However, our data does not support this assumption.

The result of the $\chi^{2}$ test corresponding to the variable [Stokes quadrant] indicates that we cannot reject the null hypothesis about independence in the research orientation (H4) as the p-value is 0.62 . Thus, there are no differences between SSH and STEM researchers in terms of their distribution within the Stokes quadrant. Previous studies found differences between the humanities and STEM, the former being more oriented toward fundamental understanding (Gulbrandsen and Kyvik 2010) and the latter more concerned with the use and relevance of the research (Hughes et al. 2011). However, contrary to what was expected, our data do not support differences in the way in which researchers orient their research. Indeed, based on this result, we cannot assert that the lack of visibility of SSH research is due to differences in the way they conduct or orient their research. Differences from previous studies could potentially be due to the fact that our analysis also includes social science disciplines (excluding arts disciplines). Nevertheless our data results move us to rejecting the idea of a difference between SSH and STEM researchers in terms of research orientation.

\subsubsection{Are SSH disciplines differently useful to STEM} disciplines? For the variables suggesting that STEM research is differently useful to SSH research, the following results are found. We analyse the variable [Formality] to test H5, whether SSH and STEM researchers use similar nature of pathways to engage with users. Our data supports the view that SSH researchers tend to use few formalised activities to collaborate with non-academic actors (Castro-Martínez et al. 2011). This is unsurprising: SSH research often does not need to subscribe to contracts to agree to the confidentiality, protection and exclusivity of the research since this knowledge does not lose value when it is shared. Conversely, the use of formal agreements to protect STEM research output though patents is more usual, because their results may lose market value if they are disseminated before they are protected.

The result of testing H6 [Popularisation] indicates that we can reject the null hypothesis (p-value $=0.00)$ and that SSH researchers spend significantly more time in this type of activities than STEM researchers. This result is in line with what some previous studies predict (Kyvik 1994, 2005), implying that SSH researchers are willing to disseminate their research beyond academia and to integrate it into public life because they have always considered contributing to the culture of society to be part of their core activities, whilst for STEM researchers, engagement in these activities is a more recent phenomenon.

Finally, we focus on the set of agents with whom researchers collaborate, that is, to the null hypotheses related to differences in the type of users. We propose that there would be statistical differences in both the intensity to which researchers are engaged with a specific user, and the diversity of pathways through which these collaborations take place. We test the intensity of these collaborations through the following hypotheses: H7a [Firms], H8a [Government agencies] and H9a [NPO]; and the diversity of the pathways used to collaborate through the hypotheses H7b [Firms_pathways], H8b [Government_pathways] and H9b [NPO_pathways]. Mann-Whitney test results indicate that for all six hypotheses, we can reject the null hypotheses as the p-values are lower than $1 \%$.

The literature predicts that SSH researchers collaborate less with firms, and more with public bodies and non-profit organisations compared to STEM researchers, which is confirmed by our empirical data, as indicated by the means for the SSH and STEM presented in Table 4 for these variables. Of course, these results should be nuanced in the context of the knowledge economy, where the SSH are highly involved in corporate development, for example through research around the concepts of organisational learning, organisational management and human resources, which are essential to the knowledge-based economy. Likewise art and humanities are also increasingly important in the emerging cultural and creative sectors (European Commission 2010).

Our findings have been compared to a similar study conducted by Hughes et al. (2011) in the UK (see the last two columns of Table 4). The comparability of these studies is somewhat reduced by the fact that, unlike comparing the SSH and STEM, Hughes et al. (2011) compare arts and humanities with all other areas (including social sciences as well as STEM). Moreover, our analysis goes one step beyond a descriptive study through our use of inferential statistical analysis. Taking these considerations into account, we find that the results from Hughes et al. (2011) point in the same direction as ours except for two variables: [Stokes quadrant] and [Government agencies]. Overall, our results confirm those found in the UK context and add richness to the study since we statistically test the hypotheses to assess whether different usefulness can be inferred from researchers' practices.

\section{Conclusions}

The results as presented above-with the necessary caveat that they are at best exploratory-give an interesting insight into the nature of the differential utility of SSH and STEM research. The first point is that the evidence does not support the claim that SSH researchers' practices 
make them less useful to societal users than STEM researchers. They feel as much demand from direct users, they are willing to work with users around testing the validity of their findings, and they are certainly not more blue sky when measured in terms of the Stokes classification. They have a much higher orientation towards users that are visible nationally (and regionally) than do STEM researchers, but that does not conclusively demonstrate that SSH research has less use because of the other indications that suggest that although more oriented to national communities, they are just as user-oriented. ${ }^{5}$ Indeed, one could then conceivably argue that $\mathrm{SSH}$ research does more to create national impact, something increasingly important in times of crisis. The conclusion of this would be that it would make sense for policy-makers to invest more in SSH research than in STEM research to drive recovery because that investment would be more likely to create national benefits. Of course, we would draw back from making that argument because of our research's exploratory nature, but we do believe that this counterintuitive finding is suggestive of more research being needed in this area.

The second finding relates to where the material differences between STEM and SSH research are to be found: clearly, STEM and SSH research are characterised by different types of usability. SSH researchers tend to use less formal pathways to engage with visible users, and it is formal pathways that are more easily tracked and measured. SSH researchers are far more likely to become involved in popularisation activities than are STEM researchers, they participate in outreach activities for a mass 'public' audience. STEM researchers work with visible users who are relatively homogenous in terms of the types of things they seek-process inputs creating economic growth-while SSH researchers work with visible users who have a much more diverse range of uses for knowledge.

Returning to our opening question, these results provide a clear answer. The question we originally posed was:

Is social sciences and humanities research different to science, technology, engineering and mathematics research in ways that make it systematically less useful to society?

Our findings suggest that SSH research is different to STEM research, but not in ways that make it systematically less useful to society, thus corroborating the contention of Nightingale and Scott (2007). This likewise contradicts van Langenhove's perception that SSH scholars idealise themselves as living in ivory towers. While scholars may themselves say that that is what they think they do, this question was not asked in the survey. When we look concretely at what the researchers reported doing, the SSH researchers surveyed were not involved in practices that were less useful than those of the STEM researchers: there were visible users for SSH research just as there were visible users for STEM research. In turn, the existence of visible users suggests a group of entities that find CSIC SSH research useful.

More research is needed to replicate this work in other national contexts. An important issue to address is the importance of differing demand and environmental conditions between SSH and STEM research. It is not clear that conceptualising the way the social value of SSH research arises within an innovation system framework makes sense. The fragmented, diffuse and indirect relationships between actors and the relatively limited roles that individual knowledge producers play in the eventual incorporation of SSH knowledge appear to shape practices in a deep-seated way which allows relatively comparable usability of the emerging knowledge.

Likewise, our findings suggest that $\mathrm{SSH}$ research does differ from STEM research in the way that it creates social value: not by working directly with businesses but in a less visible way, creating content for the media, and working with government and NPOs to contribute to improving the quality of life. These findings are not surprising, because they are suggested in the literature (Bate 2011). Our research contributes by substantiating these points with the finding that the fact that they do not always provide direct economic utility is not accompanied by a lower practical orientation towards utility. The literature provides good explanations why these differences might exist. However, the fact that they exist suggests that new and better ways need to be found to understand how SSH research creates social value, and to re-embed these understandings in conceptual frameworks for research valorisation more generally.

This finding raises the interesting question of why this discursive distortion fallacy has emerged in the policy discourse, and there are a number of potential explanations that warrant further investigation. The first would be that there has been a change, and SSH research used to be less useful than STEM research, but has changed and over time the policy discourse will itself evolve to reflect this change. The second would be that it is a result of the differential availability of statistics, and a general stronger trust and acceptance of statistics based on economic criteria. The third would be that it is an irrational belief that has become embedded in discourses and is sufficiently attractive to persist despite the contradictions that it raises. We therefore see that research is also needed into the behaviour of policy-makers, in order to understand if they are adapting to this message, and how these new and better ways of understanding value can become implemented in policymaking and science instruments.

\section{Acknowledgements}

The authors acknowledge the Spanish Council for Scientific Research (CSIC) and other researchers belonging to the IMPACTO project (INGENIO and (IESA) Institute for Advanced Social Studies) for their hard and very 
satisfactory work and the researchers who have collaborated, with their answers, in the development of the database. The authors acknowledge the Center for Higher Education Policy Studies (CHEPS) as the host institution of Julia Olmos Peñuela during her fellowship. The authors wish to thank Andrea Kottmann (CHEPS) and Richard Woolley, Elena Mas Tur, Pablo D' Este and Jaider Vega Jurado (INGENIO) for their valuable comments on theoretical and methodological aspects, also Anete Vitola and Philippe Laredo for their comments on an earlier version of this paper. Thanks are also due to the editors of Science and Public Policy and two anonymous referees for their assistance in improving the manuscript. Any errors or omissions remain the responsibility of the authors.

\section{Funding}

This work was supported by the Spanish Council for Scientific Research (CSIC) through the IMPACTO project [Ref. 200410E639] and by the Ministry of Education, which funded the $\mathrm{PhD}$ research fellowship of Julia Olmos Peñuela through the F.P.U program [AP200701850]. The research fellowship took place in the framework of the HERAVALUE project, Measuring the public value of arts and humanities research, financially supported by the HERA Joint Research Programme, cofunded by AHRC, AKA, DASTI, ETF, FNR, FWF, HAZU, IRCHSS, MHEST, NWO, RANNIS, RCN, VR and The European Community FP7 2007-2013, under the Socio-economic Sciences and Humanities programme.

\section{Notes}

1. According to the quadrants proposed by Stokes (1997): Bohr's quadrant represents research concerned solely with the pursuit of fundamental understanding; Edison's quadrant represents research solely interested in considerations of use; and Pasteur's quadrant represents the combination of both fundamental understanding and considerations of use.

2. CSIC is divided into eight scientific areas: humanities and social sciences; biology and biomedicine; food science and technology; materials science and technology; physical science and technology; chemical science and technology; agricultural sciences; natural resources. These last seven scientific areas belong to STEM.

3. The research institutes from CSIC involved in the IMPACTO project were INGENIO (Institute of Innovation and Knowledge Management) and IESA (Institute for Advanced Social Studies).

4. Following CSIC's organisational level, scientific civil servants can hold the categories of tenured scientist, scientific researcher and research professor. Teachers and professors from universities which are attached to
CSIC have been included in the category of tenured scientist and research professor, respectively.

5. One could conceive, for example, that some STEM subjects, such as agriculture, are more locally oriented, and some SSH subjects, such as philosophy, are more universally oriented. This would therefore be an emergent disciplinary property than related to the societal usefulness of that research.

\section{References}

Abreu, M. and Grinevich, V. (2013) 'The nature of academic entrepreneurship in the UK: Widening the focus on entrepreneurial activities', Research Policy, 42: 408-22.

—_ - Hughes, A. and Kitson, M. (2009) 'Knowledge exchange between academics and the business, public and third sectors'. Cambridge, UK: Centre for Business Research and UK-IRC, <http://www.cbr.cam.ac.uk/pdf/Aca demicSurveyReport.pdf $>$ accessed 17 September 2013.

Adviesraad voor Wetenschaps. (2007) Alfa en Gamma stralen. Valorisatiebeleid voor de Alfa- en Gammawetenschappen. Rijswijk: Adviesraad voor Wetenschaps- en Technologiebeleid.

Algra, K., Bennis, H., van Henten, J. W., Kemperink, K. et al. (2011) 'Quality indicators for research in the humanities'. Amsterdam: KNAW, <https://www.knaw.nl/shared/resources/ actueel/publicaties/pdf/20111024.pdf $>$ accessed 17 September 2013.

Alrøe, H. F. and Kristensen, E. S. (2002) 'Towards a systemic research methodology in agriculture: Rethinking the role of values in science', Agriculture and Human Values, 19: 3-23.

Arts and Humanities Research Council. (2009) 'Leading the world. The economic impact of UK arts and humanities research'. London: Arts and Humanities Research Council, $<$ http://www.ahrc.ac.uk/News-and-Events/Publications/ Documents/Leading-the-World.pdf $>$ accessed 17 September 2013.

Azagra-Caro, J. M. (2007) 'What type of faculty member interacts with what type of firm? Some reasons for the delocalisation of university-industry interaction', Technovation, 27: 704-15.

Bakhshi, H., Schneider, P. and Walker, C. (2008) 'Arts and humanities research and innovation'. London: Arts and Humanities Research Council and NESTA, <http://www.ne sta.org.uk/library/documents/arts-humanities-innovation-rep ort.pdf $>$ accessed 17 September 2013.

$\longrightarrow$ - and (2009) 'Arts and humanities research in the innovation system: The UK example', Cultural Science, 2: $1-23$.

Bate, J. (2011) The Public Value of the Humanities. London: Bloomsbury.

Bigelow, J. (1998) 'Valuing humanities research', in Knowing Ourselves and Others: The Humanities in Australia into the 21st Century, Vol. 3, Reflective Essays, Australian Academy of the Humanities (ed.), pp. 37-58. Canberra: Commonwealth of Australia.

Bonaccorsi, A. and Piccaluga, A. (1994) 'A theoretical framework for the evaluation of university-industry relationships', $R \& D$ Management, 24: 229-47.

British Academy. (2004) "That full complement of riches": The contributions of the arts, humanities and social sciences to the nation's wealth'. London: British Academy, <http://www.brit ac.ac.uk/templates/asset-relay.cfm?frmAssetFileID = 6386> accessed 17 September 2013. 
(2008) 'Punching our weight: The humanities and social sciences in public policy making'. London: British Academy, <http://www.allea.org/Content/ALLEA/WG\%20 Evaluating/Punching_our_weight.pdf $>\quad$ accessed 17 September 2013.

Bullen, E., Robb, S. and Kenway, J. (2004) ' "Creative destruction": Knowledge economy policy and the future of the arts and humanities in the academy', Journal of Education Policy, 19: 3-22.

Castro-Martínez, E., Molas-Gallart, J. and Olmos-Peñuela, J. (2011) 'Knowledge transfer in the social sciences and the humanities: Informal links in a public research organization'. Paper presented at Atlanta Conference on Science and Innovation Policy, held 15-7 September 2011, Atlanta, GA.

Cohen, W. M., Nelson, R. R. and Walsh, J. P. (2002) 'Links and impacts: The influence of public research on industrial R\&D', Management Science, 48: 1-23.

Crossick, G. (2009) 'So who now believes in the transfer of widgets?'. Talk given at the Knowledge Futures Conference, held 16-7 October 2009, London <http://www.london.ac.uk/ fileadmin/documents/about/vicechancellor/So_who_now_ believes_in_the_transfer_of_widgets.pdf $>$ accessed -17 September $201 \overline{3}$.

CSIC. (2012) 'Memoria anual del CSIC 2011'. Madrid: Consejo Superior de Investigaciones Científicas, <http://documenta. wi.csic.es/alfresco/downloadpublic/direct/workspace/Spaces Store/81d3f71c-819c-4787-9147-8c18b2d64fcb/CSIC_MEMO RIA_2011_alta.pdf $>$ accessed 17 September 2013.

D'Este, P. and Patel, P. (2007) 'University-industry linkages in the UK: What are the factors underlying the variety of interactions with industry?', Research Policy, 36: 1295-313.

Dillman, D. A. (2007) 'Survey implementation'. In: Dillman, D. A. (ed.) Mail and Internet Surveys: The Tailored Design Method, pp. 150-93. Hoboken: NJ: Wiley.

Directorate General Research. (2011) 'Innovation Union Competitiveness Report 2011'. Brussels: Directorate General Research, <http://ec.europa.eu/research/innovation-union/ind ex_en.cfm?section $=$ competitiveness-report\&year $=2011$ > accessed 17 September 2013.

Donovan, C. (2005) 'The governance of social science and everyday epistemology', Public Administration, 83: 597-615.

Edgar, A. and Pattison, S. (2006) 'Need humanities be so useless? Justifying the place and role of humanities as a critical resource for performance and practice', Medical Humanities, 32: 92-98.

European Commission. (2010) 'Unlocking the potential of cultural and creative industries', Green Paper, COM(2010) 183. Brussels: European Commission <http://ec.europa.eu/ culture/documents/greenpaper_creative_industries_en.pdf > accessed 17 September 2013.

Gascoigne, T. and Metcalfe, J. (2005) 'Commercialisation of research activities in the humanities, arts and social sciences in Australia', Council for Humanities, Arts and Social Sciences Occasional Paper No. 1. Canberra: Council for Humanities, Arts and Social Sciences <http://www.chass.org.au/papers/ pdf/PAP20050501TG.pdf $>$ accessed 17 September 2013.

Geuna, A. and Muscio, A. (2009) 'The governance of university knowledge transfer: A critical review of the literature', Minerva, 47: 93-114.

Gray, J. (1992) Men are from Mars, Women are from Venus. London: HarperCollins.

Gulbrandsen, M. and Kyvik, S. (2010) 'Are the concepts basic research, applied research and experimental development still useful? An empirical investigation among Norwegian academics', Science and Public Policy, 37: 343-53.

Hartley, J. and Cunningham, S. (2001) 'Creative industries: From blue poles to fat pipes'. Paper presented at National
Humanities and Social Sciences Summit, held July 2001, Canberra.

Hessels, L., van Lente, H. and Smits, R. (2009) 'In search of relevance: The changing contract between science and society', Science and Public Policy, 36: 387-401.

Hughes, A., Kitson, M., Probert, J., Bullock, A. and Milner, I. (2011) 'Hidden connections: Knowledge exchange between the arts and humanities and the private, public and third sectors'. Cambridge, UK: Arts and Humanities Research Council and Centre for Business Research, <http://www. ahrc.ac.uk/News-and-Events/Publications/Documents/

Hidden-Connections.pdf $>$ accessed 17 September 2013.

Jaaniste, L. (2009) 'Placing the creative sector within innovation: The full gamut', Innovation: Management, Policy and Practice, 11: 215-29.

Jensen, P. and Croissant, Y. (2007) 'CNRS researchers' popularization activities: A progress report', Journal of Science Communication, 6: 1-13.

Kaiser, R. and Prange-Gstöhl, H. (2010) 'A paradigm shift in European R\&D policy? The EU budget review and the economic crisis', Science and Public Policy, 37: 253-65.

Kyvik, S. (1994) 'Popular science publishing', Scientometrics, 31: $143-53$

- (2005) 'Popular science publishing and contributions to public discourse among university faculty', Science Communication, 26: 288-311.

Leisyte, L. and Horta, H. (2011) 'Introduction to a special issue. Academic knowledge production, diffusion and commercialization: Policies, practices and perspectives', Science and Public Policy, 38: 422-24.

Molas-Gallart, J. and Tang, P. (2011) 'Tracing 'productive interactions' to identify social impacts: An example from the social sciences', Research Evaluation, 20: 219-26.

- _ and Castro-Martínez, E. (2010) 'Social impact assessment in the social sciences and humanities: An application of the SIAMPI approach', SIAMPI Project, Workpackage 6 Report, $<$ http://www.ingenio.upv.es/sites/default/files/adjuntos_desc_ proyectos/SIAMPI_D6_2_Final_report_Social_Sciences_ and_Humanities.doc.pdf $>$ accessed $17 \overline{\text { September }} 2013$.

Nightingale, P. and Scott, A. (2007) 'Peer review and the relevance gap: Ten suggestions for policy-makers', Science and Public Policy, 34: 543-53.

O'Neill, O. (2011) 'Foreword'. In: Bate, J. (ed.) The Public Value of the Humanities, pp. v-viii. London: Bloomsbury.

OECD. (2002) 'The Measurement of Scientific and Technological Activities', Frascati Manual 2002: Proposed Standard Practice for Surveys on Research and Experimental Development. Paris: OECD.

Olmos-Peñuela, J., Benneworth, P. and Castro-Martínez, E. (2012) 'Are STEM from Mars and SSH from Venus? A comparison of research and transfer activities in the hard and soft disciplines', Working paper presented at Center for Higher Education and Policy Studies, Enschede, The Netherlands, 18 January 2012.

Pavitt, K. (1991) 'What makes basic research economically useful?', Research Policy, 20: 109-19.

Perkmann, M. and Walsh, K. (2007) 'University-industry relationships and open innovation: Towards a research agenda', International Journal of Management Reviews, 9: 259-80.

Pilegaard, M., Moroz, P. W. and Neergaard, H. (2010) 'An autoethnographic perspective on academic entrepreneurship: Implications for research in the social sciences and humanities', Academy of Management Perspectives, 24: 46-61.

Schartinger, D., Rammer, C., Fischer, M. M. and Frohlich, J. (2002) 'Knowledge interactions between universities and 
industry in Austria: Sectoral patterns and determinants', Research Policy, 31: 303-28.

Spaapen, J. and van Drooge, L. (2011) 'Introducing "productive interactions" in social impact assessment', Research Evaluation, 20: 211-8.

Stannage, T. and Gare, D. (2001) 'Partnerships and collaborations: The importance to humanities, social sciences and creative arts'. Paper presented at National Humanities and Social Sciences Summit, held July 2001, Canberra.

Stokes, D. E. (1997) 'Pasteur's Quadrant: Basic Science and Technological Innovation. Washington, DC: Brookings Institution Press.
Toulmin, V. (2011) 'This is a local film. The cultural and social impact of the Mitchell \& Kenyon film collection'. In: Bate, J. (ed.) The Public Value of the Humanities, pp. 87-102. London: Bloomsbury.

Van Langenhove, L. (2012) 'Global issues: Make social sciences relevant', Nature, 484/7395: 442.

Van Vught, F. A. and Westerheijden, D. F. (2010) 'Multidimensional ranking: A new transparency tool for higher education and research', Higher Education Management and Policy, 22/3: 1-26.

\section{Appendix}

Table A1. Summary of hypotheses

H1. The rate of involvement with national users compared to international users is higher for SSH researchers than for STEM researchers

H2. SSH researchers experience a lower demand for their research than is the case for STEM researchers

STEM is more useful than SSH

H3. SSH researchers have less interest in checking the validity and applicability of their research than do STEM researchers

H4. SSH researchers are more concerned with the pursuit of fundamental understanding whereas STEM researchers are more focused on considerations of use

H5. SSH researchers use a lower proportion of formal pathways to interact with non-academic actors compared to STEM researchers

H6. SSH researchers spend more time in popularisation activities than do STEM researchers

H7a. SSH researchers collaborate less with firms than do STEM researchers

H7b. SSH researchers use fewer pathways collaborating with firms than do STEM researchers

STEM is differently useful to SSH H8a. The frequency of collaborations with government agencies compared to firms is higher for SSH researchers than for STEM researchers

H8b. SSH researchers use more pathways collaborating with government agencies than do STEM researchers

H9a. The frequency of collaborations with non-profit organisations compared to firms is higher for SSH researchers than for STEM researchers

H9b. SSH researchers use more pathways collaborating with non-profit organisations than do TEM researchers

Table A2. Structure of questionnaire

\begin{tabular}{|c|c|c|}
\hline Conceptual dimensions & Description & Number of questions \\
\hline $\begin{array}{l}\text { Researchers' profile and research } \\
\text { activities }\end{array}$ & $\begin{array}{l}\text { Includes questions related to researchers' opinions and attitude } \\
\text { towards their work and their relationships with other entities. It also } \\
\text { addresses their sources of research funds, as well as the characteris- } \\
\text { tics of their academic activities }\end{array}$ & $\begin{array}{l}\text { Characteristics of the research } \\
\text { activity: } 5 \text { questions } \\
\text { Researchers' profile: } 8 \text { questions }\end{array}$ \\
\hline $\begin{array}{l}\text { Relationships with other entities } \\
\text { in the socio-economic } \\
\text { environment }\end{array}$ & $\begin{array}{l}\text { Collects information about the frequency and type of relationships in } \\
\text { which researchers engage with different public/private entities (e.g. } \\
\text { firms, government agencies, international organisations, non-profit } \\
\text { organisations). It also addresses researchers' perceptions of the } \\
\text { interest of these entities in their research, researchers' motivations to } \\
\text { establish these relationships and how these were initiated }\end{array}$ & $\begin{array}{l}\text { Relationships with other entities of } \\
\text { the socio-economic environment: } 6 \\
\text { questions }\end{array}$ \\
\hline $\begin{array}{l}\text { Obstacles and aspects that influ- } \\
\text { ence the development of rela- } \\
\text { tionships with other entities }\end{array}$ & $\begin{array}{l}\text { Contains information regarding obstacles found by researchers to es- } \\
\text { tablishing relationships with other entities as well as the institutional } \\
\text { support received to initiate and manage these relationships }\end{array}$ & $\begin{array}{l}\text { Obstacles and aspects that influence } \\
\text { the relationships: } 7 \text { question }\end{array}$ \\
\hline Outreach & $\begin{array}{l}\text { Includes activities related to dissemination and social communication } \\
\text { of researchers' scientific activities. Questions address researchers' fre- } \\
\text { quency of engagement in these activities, as well as the relevance } \\
\text { and influence of their scientific work }\end{array}$ & $\begin{array}{l}\text { Activities related to diffusion and } \\
\text { social use of science: } 3 \text { questions }\end{array}$ \\
\hline
\end{tabular}

